\title{
THE SOCIAL LIFE OF HISTORICAL NEIGHBOURHOODS: CASE STUDY OF A MIDDLE EASTERN CITY, SHIRAZ
}

\author{
Leila Mahmoudi FARAHANI ${ }^{a}$, Mirjana LOZANOVSKA ${ }^{b}$,
}

\author{
School of Architecture and Built Environment, Deakin University, 1 Gheringhap Street, Geelong, 3220, Australia \\ E-mails:almahmoud@deakin.edu.au (correspondingauthor); bmirjana.lozanovska@deakin.edu.au;
}

Received 01 March 2015, accepted 01 July 2015

\begin{abstract}
Historic neighbourhoods have usually shaped on an organic structure in regard to their residents' requirements. Due to the limitations in mobility, historical neighbourhoods were usually able to perform as a small city comprising all the elements required for satisfying physical, social, and cultural needs. This paper seeks to explore the patterns of social life in the traditional settlements in Shiraz and investigate the elements that have shaped the social life of these neighbourhoods. Exploring the social structure of historic neighbourhoods may introduce new approaches to the design of contemporary suburbs and neighbourhoods in terms of their vitality and social life. A review of the literature and comparing it to the historical core in Shiraz shows that there are five contributing factors to the social life of historic neighbourhoods in Shiraz, including density, human scale development, walkability, mixed land-use and qualities of public spaces. Exploring the features of public places and communal facilities indicates that the fine social performance of these settlements is rooted in their compatibility and adaptability to the environment, the residents' requirements and culture.
\end{abstract}

Keywords: social life, historical neighbourhood, community, urban design, sense of community, vitality.

\section{Introduction}

Public life and the neighbourhood environment were historically a cohesive unit. Historical neighbourhoods have evolved little by little, in accordance with their residents' changing needs. Residents' requirements had to be satisfied within the neighbourhood's boundaries and through their commitments to the local communities. Historically, neighbourhoods were places with a high number of interactions among residents. However, in today's cities, territory is not a prerequisite for social interactions among urbanites, and accordingly, residents' increasing involvement in non-local communities has led some neighbourhoods to suffer from a lack of vitality and social life.

One way of approaching the problem of social life in neighbourhoods is through the physical environment and architectural characteristics. Many studies have found a correlation between physical, built environment characteristics and feeling a sense of community (Francis et al. 2012; Kim, Kaplan 2004; Talen 2000). Interestingly, these studies are not limited to the built environment discipline. According to community psychologists such as Plas and Lewis, environmental factors may be crucial for the development of a sense of community in urban communities (Plas, Lewis 1996). Cohran also argues that planners are able to preserve and strengthen a neighbourhood's sense of community through both social policies and physical design strategies (Cohrun 1994).

Investigating the physical characteristics that have enriched the social life of historic neighbourhoods may introduce new approaches and prospects to the literature of the built environment focusing on the social life of neighbourhoods. It is indisputable that a historic model of social life in a specific city cannot be parameterized and be reproduced as a model to design other cities and contemporary environments. However, the historical insights and the conventional wisdom employed in the development and planning of unavoidable walkable and liveable neighbourhoods might be inspirational for the development and revitalization of contemporary neighbourhoods.

Historic neighbourhoods in most cities of Iran formed gradually in response to dwellers' communal and social needs and thus can be considered as fine 
examples of integrated public life, vitality and strong ties among residents. Therefore, the focus of this study is to explore the built environment features that are considered effective in reinforcing the social life of traditional settlements in Shiraz.

In old Shiraz, the social life of neighbourhoods (mahallehs) is the interface of the private life of the residents and the social life of the whole city. Alongside residential streets, historical neighbourhoods of Shiraz consist of public spaces and public uses, which host communal activities. Public buildings and public places have been shaped with regard to the hierarchy of the social life in the city. Most communal elements that can be found in neighbourhoods (such as mosques, schools, squares and bazaar), can be seen in a much larger scale in the city centre and these are the focal points for gathering all the residents in special events and rituals.

This study aims to explore the existing literature focused on social life of streets and define the built environment characteristics that have been considered as effective in determining the social life of neighbourhoods. This paper will also discuss the defined characteristics in the context of old Shiraz and investigate the nature of social elements and public spaces that have been efficacious communal features throughout the history of Shiraz's neighbourhoods.

\section{Shiraz formation}

The city of Shiraz is more than 2000 years old. It is the fifth most populous city of Iran and serves as a fine example of Iranian old cities in the hot and arid climate. The case study of this research is the historic district of Shiraz, which consists of eleven neighbourhoods and dates back to the Islamic era. These neighbourhoods have been emerged gradually, based on socioeconomic, religious, occupational, ethnic and environmental factors (Fig. 1).

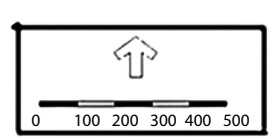

1. Darb-e-Shazdeh

2. Meydan Shah

3. Sang-e-Siah

4. Sar-e-Dozak

5. Sar-e-Bagh

6. Darb-e-Masjed

7. Kalimiha

8. Bazaar Morgh

9. Lab-e-Aab

10. Baalaa Kaft

11. Eshagh Beyg

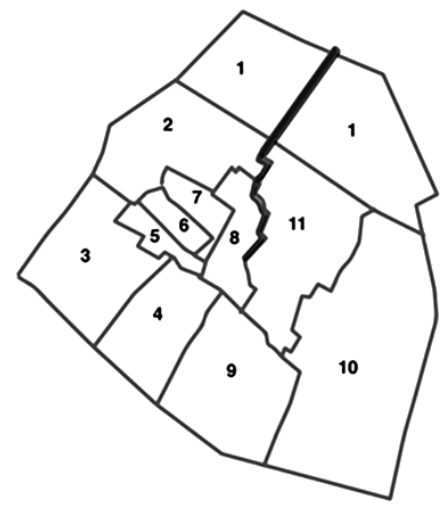

Fig. 1. The map of Shiraz old neighbourhoods (created by the author based on Behpoor map 1383)
In order to study the social life in a historical city, an understanding of how the city has been formed through history can facilitate the investigation of these social patterns. Debates regarding the formation of Iranian historical cities include the role of water channels (Bonine 1979) and socio-cultural factors such as bazaars (Soltanzadeh 1986). In Shiraz, both the irrigation system and bazaar seem to be critical factors in the creation and formation of the old city. The geographical situation of Shiraz and its placement in the central part of Iran, near deserts with limited water resources, are the proof of the significance of the irrigation system for Shiraz planning. As the irrigation system was mostly through ghanats $^{1}$, the everyday use of water reservoirs in neighbourhood centres as communal facilities provided a reason for interactions among neighbours. Ghanats' water was accessible through water reservoirs in neighbourhood centres. Distribution of these water reservoirs through neighbourhoods and the frequency of use made them a popular focal point for the establishment of social relationships, regular contacts and exchange of greetings.

Additionally, as Shiraz was historically a commercial city, Vakil Bazaar was one of the main elements in its historical urban plan. Shiraz's position near the Persian Royal Road, an ancient road reorganized and rebuilt by the Persian king Darius the Great (Darius I) of the Achaemenid Empire in the 5th century BC, made the city a commercial intermediate in this route. Furthermore, bazaars in Iranian historical cities are comparable to plazas in European pre-industrial cities (not for their physical form, because, environmentally speaking, meydan (square) is more similar to plazas but for their social value). Similar to plazas, agora and forum in Europe, the bazaar was also a meeting space, a place for social, political, cultural and civic activities of people alongside its commercial figure (Motamed 2000).

\section{Social life: meaning and implication}

Public life has been defined as everything that occurs between buildings: walking, sitting, chatting, cycling, running, standing and playing, which form 'the life between buildings' (Gehl 1987). As Bianchini (1999) illustrates, public social life is "the interacting of socialising or sociability...that occurs within the public realm". During the period of rapid urban growth, the social life between buildings was disregarded as a result of automobile dependency, large-scale designing and

\footnotetext{
${ }^{1}$ Ghanats were reliable supply system of water for human settlements and irrigation in hot, arid and semi-arid climates. Iranian old cities with hot temperature life Yazd and Shiraz used ghanats to provide water for their residents.
} 
overly rationalized, specialized processes (Farahani, Lozanovska 2014). Gehl and Svarre argue that in past, city design and social life were interconnected and were produced through their natural cycle, but since industrialization, the social life has been detached from the process of urban design (Gehl, Svarre 2013).

Social life studies started in the 1960s, when the criticism of modern architecture and urbanization was peaking due to the neglect of social needs and marginalizing human interactions. Consequently, public life studies were initiated by scholars such as Jacobs and Gehl, who are considered as the key authors in this area of knowledge. Jacobs stresses the importance of high-density neighbourhoods, mixed land-use and the promotion of public places in cities. She believes that the physical structure of cities can lead to a cohesive community and life (Jacobs 1961). Later, in 1987, Jan Gehl in his book, Life Between Buildings, stresses the qualities of urban life and the way in which the built environment can encourage a social life in public places and especially city centres. He repeatedly criticizes the neglecting of the human dimension in urban design, the emergence of car-dominated cities and the loss of pedestrian-oriented environments (Gehl 1987).

Following Jacobs and Gehl, several scholars have studied the social life of public places in cities to attempt to identify the built environment characteristics that can contribute to the vitality of city centres and public spaces. Several physical characteristics have been shown to have a correlation with a sense of vitality in neighbourhoods. In historic neighbourhoods in Shiraz, the characteristics that are perceived to have a contributing role include density (Amick, Kviz 1975; Franck, Stevens 2007; Gehl 1987; Jacobs 1961; Pendola, Gen 2008; Talen 1999), mixed land-use and the presence of retails (Alexander 1977, Audirac, Shermyen 1994; Jacobs 1961; Mehta 2013;

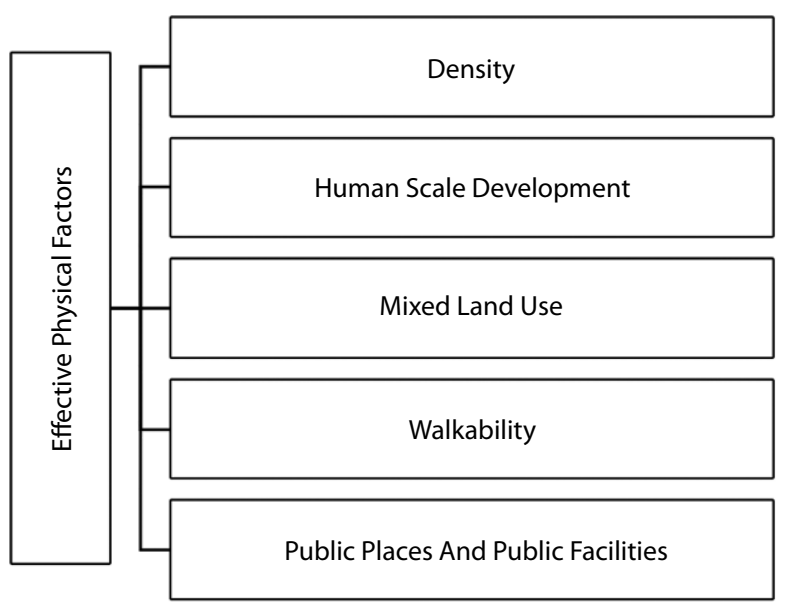

Fig. 2. Effective physical factors in terms of the social life in historic neighbourhoods of Shiraz
Montgomery 1998), human scale development (Amick, Kviz, 1975; Gehl 1987; Gehl 2010; Lockwood 1997), walkability and the placement and design of public places and public facilities (Fig. 2) (Francis et al. 2012; Mehta 2013). The spatial configuration of residential and nonresidential buildings is through a hierarchy that provides the opportunity for interactions and the creation of strong ties among residents.

\section{Investigating the social life of the historical neighbourhoods of Shiraz}

Shiraz historic neighbourhoods have had a high density, and the number of people per dwelling used to be much higher, compared to today's neighbourhoods (since people use to have more children and many children used to live in their parents' home till marriage and even in some cases after marriage). In the residential environment, density is believed to have a positive effect in the creation of vitality and life (Gehl 1987; Gehl, Gemzøe 2004). In the literature of the built environment, suburbs in which people spread out more thinly have been criticized for insufficient vitality and public life (Jacobs 1961).

Historic mahallehs of Shiraz have been designed with regard to the human scale. Several scholars believe that neighbourhoods built at a human scale can encourage people to walk more, which will indirectly proliferate the number of interactions (Franck, Stevens 2007). Gehl argues that small-scale cities are more eventful, intense and warm. In narrow streets and small spaces, we can see buildings, details and the people around us at a close range (Gehl 1987). In Shiraz, most residential developments in traditional mahallehs are single story (some have basements) and the routs are narrow and pedestrian friendly.

Mixed land-use is another built environment characteristic that can affect the social life of residential environments (Jacobs 1961; Gehl 1987; Talen 1999; Kashef 2009). A recent study by Mehta shows that the commercial street in neighbourhoods can influence the social life, land-use and the physical qualities (Mehta 2007; Mehta 2013). Encouraging these qualities will affect the public life of commercial streets and the neighbourhoods. Land-use qualities are related to the business variety, the presence of independent stores, personalization and permeability of stores. Physical qualities include commercial and public seating, sidewalk width, shade and building articulation. Social qualities relate to community gathering spaces. Mehta has developed a model of qualities that can affect enduring activities in commercial streets in neighbourhoods (Mehta 2013) (Fig. 3). In old Shiraz there are usually small markets serving the neighbouhoods' requirements placed around the 


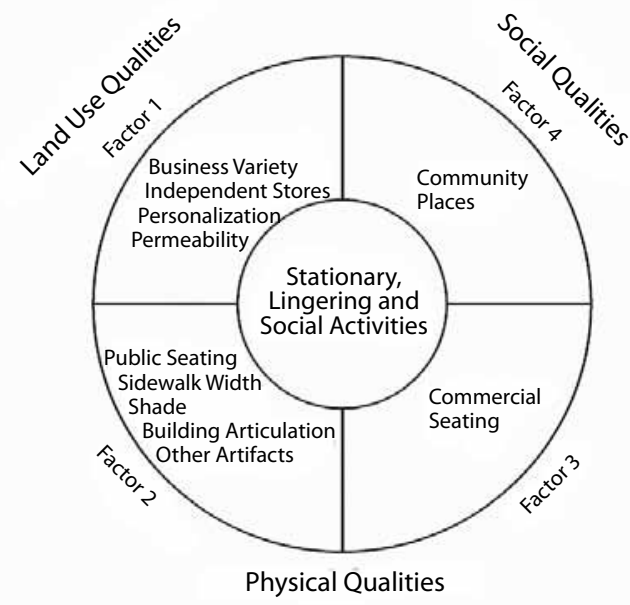

Fig. 3. Qualities of commercial streets that promote stationary activities and interactions (Mehta 2013)

neighbourhood centres, and sometimes scattered small shops has been extracted from a house to serve a locality.

Walkability is also an important factor in encouraging the social life of the old city of Shiraz. The old city has around one kilometre radius, which has been studied to be the average maximum length that people are willing to walk (Gehl 1987). The city was planned with narrow walking alleys shadowed by surrounding walls intended for thermal comfort. Numerous studies have argued the importance of walkability for human health, safety, lively cities and a sense of community (Gehl 1987; Lund 2002; Gehl 2010; Wood et al. 2010). Walking from homes to communal places in neighbourhood centres increases the number of 'coming and going' activities and the chance of encounters (Gehl 1980).

Shared spaces and public facilities in neighbourhoods are considered as the points of interaction among neighbourhood residents. Neighbourhoods are a combination of housing units (residential areas) and extended housing units (Brower 1996). Extended housing units are the place for home related facilities outside homes, such as parks, community gathering places, and commercial streets. As some of these extended housing units are shared between several houses, they are considered as points of connection, which may provide a chance of encounter for residents. Brower (1996) explains that some points of connections are mostly for neighbours and some may connect the neighbourhood's residents to the non-residents or strangers. A study of inner city neighbourhoods suggests that the use and characteristics of shared spaces and common facilities may play a vital role in the growth of a community (Kuo et al. 1998). According to Talen (1999), public spaces such as parks and civic centres also serve as symbols of civic pride and sense of place, which promote the notion of community. "If public spaces are a pleasure to inhabit, they will be used, and their usefulness as promoters of sense of community will flourish" (Talen 1999).

Not only the presence of common facilities and public spaces may affect the social life of neighbourhoods, but also their degree of publicness can have a contributing role. Historically, public spaces in cities were used as spaces to perform several political, religious, commercial, civic and social functions, while serving basic survival, communication and everyday needs. In contemporary neighbourhoods, many of these functions have relocated to private or virtual realms and are increasingly being developed and managed by private agencies. In this sense, neighbourhood gathering places may give heart to the community (Langdon 1997), and serve to lessen the pressure of community fragmentation, resulted by privatization.

Not only the presence of communal facilities and public spaces have been studied to mitigate the social life of neighbourhoods, but also the quality of public places such as parks and shops have been associated with a strong sense of community among residents. According to Francis et al. (2012), the quality of neighbourhood public spaces is an equally, if not more important, correlate of sense of community than public space size and number. Zhang and Lawson (2009) found that the size and number of public spaces outside residential buildings were not significantly associated with social interaction, concluding that the key to social interaction in public spaces was the quality of the public space and amenities provided.

The most contributing factor in encouraging the social life in Shiraz traditional mahallehs seems to be the presence and quality of public places and public amenities, which were responsible for supplying the everyday and social needs of the residents. The functionality, accessibility, and cultural role of these elements were the reasons behind their usability and social structure. This paper aims to discuss these elements throughout the following sections.

\section{Social elements (public spaces and public facilities) in historical mahallehs of Shiraz}

In the historic district of Shiraz, patterns of social life occur through public places and public facilities that have been woven into the texture of neighbourhoods. The spatial configuration of neighbourhoods has been shaped in a way that generates the social structure of the locality. Most public spaces and buildings in neighbourhoods have had a social function and designed in a multi-purpose way in response to the social needs of the locality while providing necessities of everyday life. 
Public places that will be investigated in this study are home entrances, alleys and neighbourhood centres. Public facilities in neighbourhoods consist of mosques, schools and public baths, which have usually been designed around neighbourhood centres (Fig. 4).

According to Francis et al. (2012) the perceived quality of public open spaces and facilities (such as shops) can be more important than the size and number in creating a sense of community and social life in neighbourhoods (Francis et al. 2012). This quality is also correlated with the frequency of use, which may indirectly increase the chance of interactions. Accordingly, this study suggests that investigating the social quality of public spaces and facilities seems to be able to illustrate the patterns of interactions in traditional settlements in Shiraz.

The functional/social elements in the old neighbourhoods of Shiraz were able to provide a place for the creation of local communities. Hillery, in his study on definitions of community, concluded that three elements were essential components of most definitions: a specific place, common ties and social interaction (Hillery 1955). In the old district of Shiraz, the first element of place was provided through these public buildings. Common ties were usually achieved through the homogeneity of neighbourhoods and with a function in public facilities (religious in mosques, hygiene in baths and education in schools), and the architectural characteristics of these public places and buildings were the host of social interactions.

Most of these public amenities and public spaces alongside their primary use were able to act as third places. A third place, as described by Oldenburg, is a place of refuge other than the home or workplace, where people can relax, commune and interact. They are places that satisfy social needs where one can meet friends, colleagues, neighbours and even strangers. "The best third places are locally owned, independent, small-scale, steady-state business..." (Oldenburg 1989). Many of

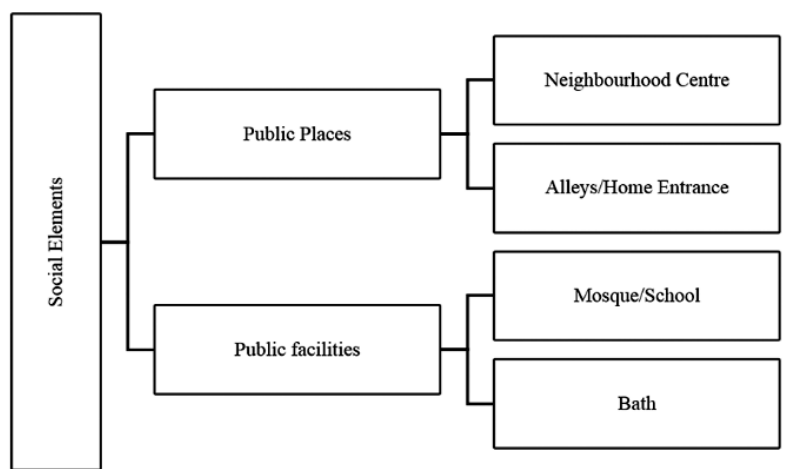

Fig. 4. Elements of social life in historical neighbourhoods of Shiraz the local amenities in Shiraz were donated by residents and locally owned and maintained. Additionally the main function of these facilities and spaces usually assure their continuous everyday use.

\section{Neighbourhood centre}

The neighbourhood (mahalleh) is the main component of the social body of Islamic cities (Khaghani 2012). The residential construction in historic Islamic cities such as Shiraz is introverted and walls indicate a sharp separation of indoor and outdoor in Iranian houses (Rapoport 2007). Therefore, the social character of neighbourhoods' public spaces was very significant in creating neighbouring relationships and strong ties among residents. The space inside mahalleh is privatised in a hierarchy from ultimately private to ultimately public (family, immediate neighbours, a section of mahalleh, mahalleh and finally the city).

Neighbourhood centres (markaz mahalleh) in the historical neighbourhoods of Shiraz were mostly a semi-public complex forming around small squares. While providing the necessary urban infrastructure and spatial arrangement, they were able to give spatial identity to each neighbourhood. This spatial division between neighbourhoods and urban public spaces were able to provide quiet and semi-private space for the residents; meanwhile providing playgrounds for children and a rendezvous for interactions.

The social life of neighbourhood centres usually depends on the functionality of the nearby elements and their everyday use. Important city elements such as beautiful monumental mosques were mostly located next to these neighbourhood centres, where people could gather in religious events, on a regular basis or even everyday (at least three times a day for daily prayers). Some of these mosques were also used as schools hosting residents of different ages. Bazaars and public baths were also important elements located nearby neighbourhood centres.

Shiraz neighbourhoods were created with a combination of residential, commercial, cultural and institutional uses and neighbourhood centres were the location of non-residential facilities. These non-residential facilities (baths, mosques, schools, bazaars, water reservoirs) were able to gather a huge range of residents, while supplying their everyday needs. Therefore, the neighbourhood centre was able to act as a social hub gathering all the functions in one place, while providing a place for interactions (Fig. 5).

Each neighbourhood with respect to its services could perform like a small city. Proximity had been a response to a life without an automobile, since traditionally resident's life was based on foot and accessibility 


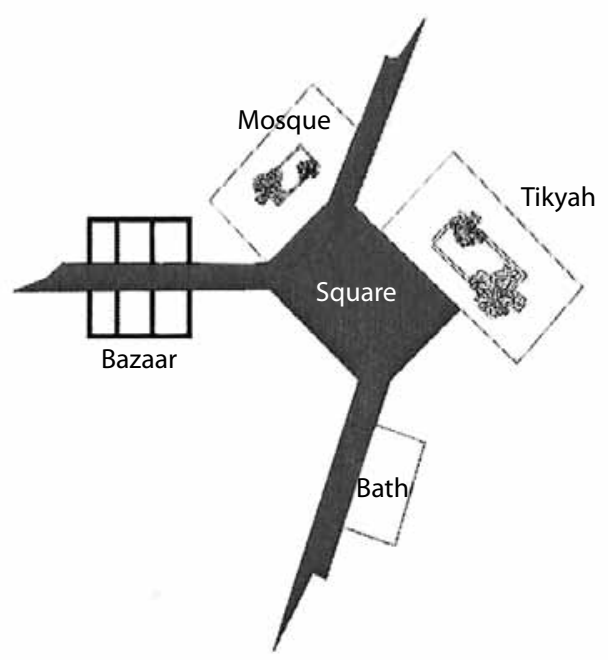

Fig. 5. Sketch of a neighbourhood centre (Khaghani 2012)

was a vital factor of commercial uses. As the commercial streets of the residential areas in the west contribute to the vitality and liveability of neighbourhoods and may even create a sense of community (two significant goals of urban design and planning), so could the neighbourhood centres in historical neighbourhoods of Shiraz.

\section{Alleys/entrance}

The street, in the old district of Shiraz, was designed in such a way as to provide a desirable temperature in hot summers, or cold windy winters. Creating narrow alleys surrounded by tall walls was the conventional wisdom to create a desirable shadow in almost every hour of the day. The narrow and twisted alleys were also considered to be a vernacular strategy in breaking the wind speed in winters. These narrow alleys were also a reason for ongoing exchanges of greetings. As Gehl argues, small-scale developments cause the residents to experience more of the city and other residents specially, in comparison with contemporary built areas which are usually sprawling out. The lack of vehicular traffic could also be an effective aspect in the vitality of these narrow alleys (Gehl 1987, Appleyard 1981). However, on the downside, the narrow structure of these alleys could not provide a suitable structure for long encounters or social activities (Fig. 6).

Historic houses in Shiraz were designed with an introverted architecture, with their entrance as the only interface between the inside and the outside. Most houses, near their entrance, had one or two seats, which were termed elderly-seats. Sometimes the house dwellers or even strangers would sit on these stone seats to rest. For some people, especially the elderly, this had become a routine to sit, spend time and interact with the neighbours passing by (Fig. 7). These seats were embedded for the

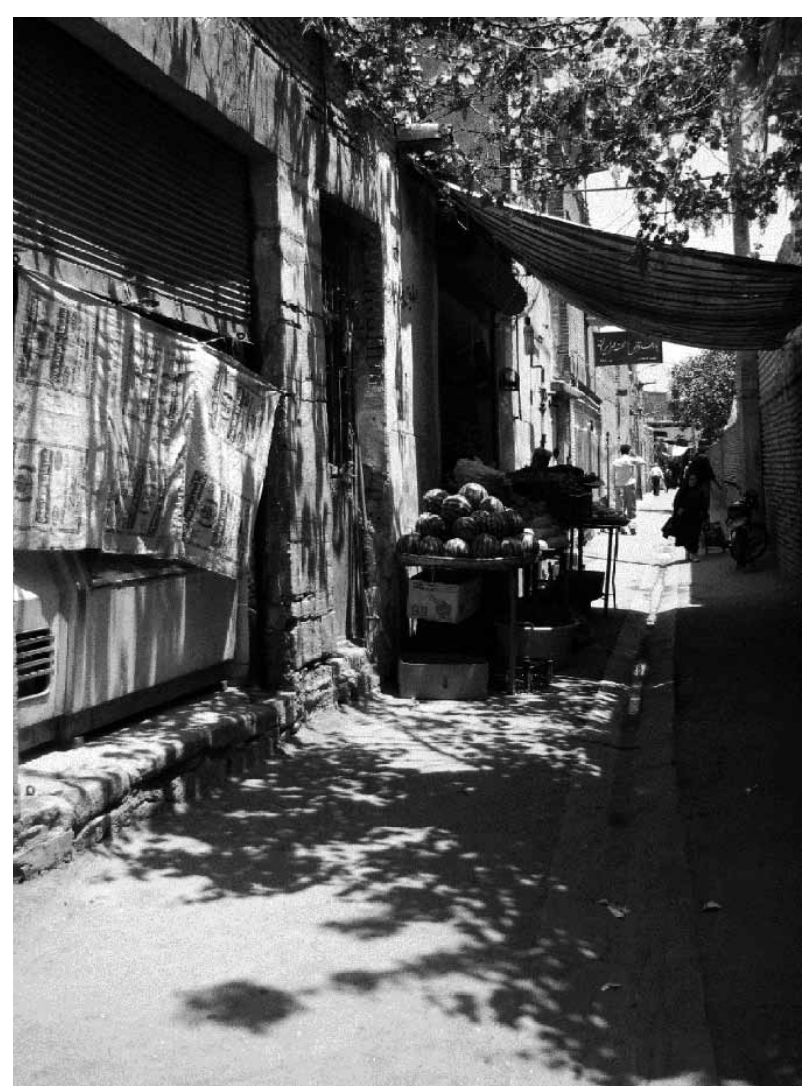

Fig. 6. Narrow alleys in old district of Shiraz (photo by the author)

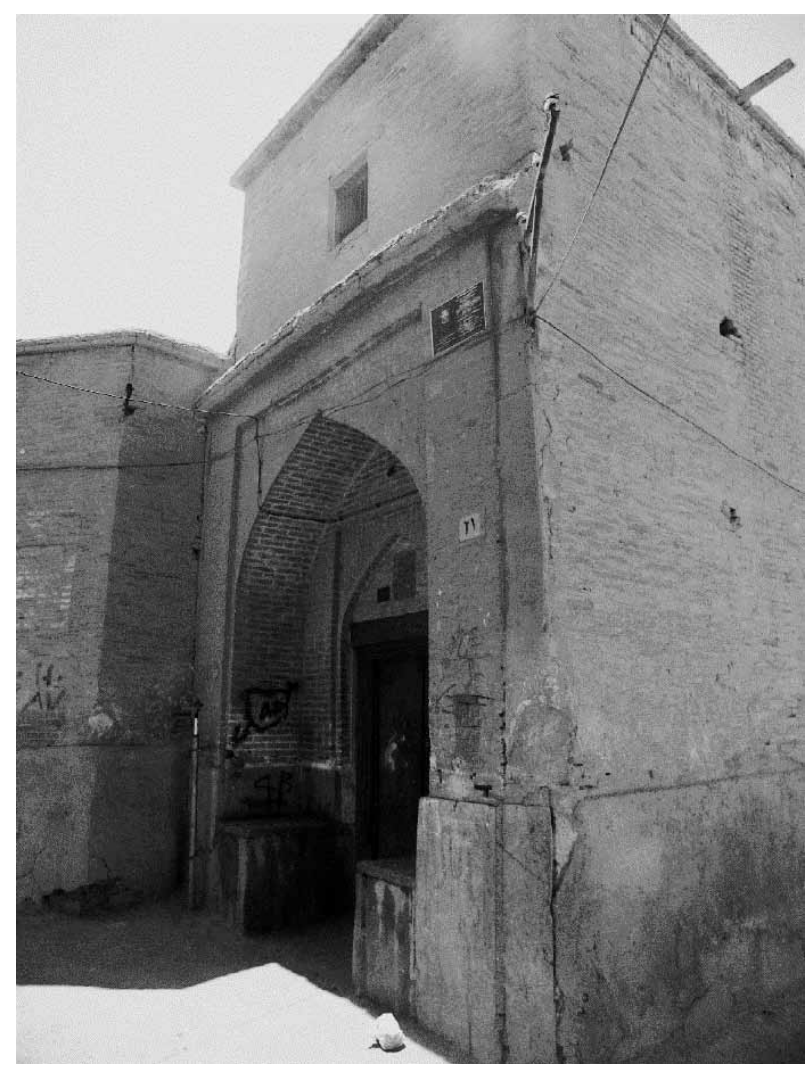

Fig. 7. Entrance with seats in old district of Shiraz (photo by the author) 
people passing through alleys to rest and put their load or shopping bags on them. These seats can be compared to front yard porches in the west, where residents sometimes perform their daily routines in a private but manifest to public area. Gehl, in his study of residential areas, found that front yards with a specific length are predominant spatial elements in promoting the social life of residential streets (Gehl et al. 2006).

\section{Mosque/school}

Mosques (masjeds) have an integral role in developing the social life of historic neighbourhoods in Iran. In Iranian Islamic cities, a mosque is not only a place for worship, but also a public place for people to interact while doing religious rituals (considering that many Islamic rituals are collective). According to Ashraf (1988) the bazaar and the mosque, as inseparable twins, have served, for many centuries, as the primary arena of public life in urban Iran. In pre-modern Iran, they were the two principal arenas of sociability outside of kinship relations. Sometimes mosques had a dual function serving some flexible spaces as a school. Until the beginning of the 20th century, mosques and schools have mostly been an integrated space, with integrated functions.

In small local mosques, the spatial configuration was flexible enough to host several functions especially educational purposes. However, in bigger, non-local mosques, usually a separate space in mosques or close to mosques was allocated to the school. For example, close to Vakil Mosque, which is a non-local mosque of Shiraz, a land has been dedicated to a school named Agha-Baba-Khan school (Fig. 8). On the other hand, in local mosques such as Moshir Mosque or Nasiralmolk Mosque, people could use the mosque's space for both functions.

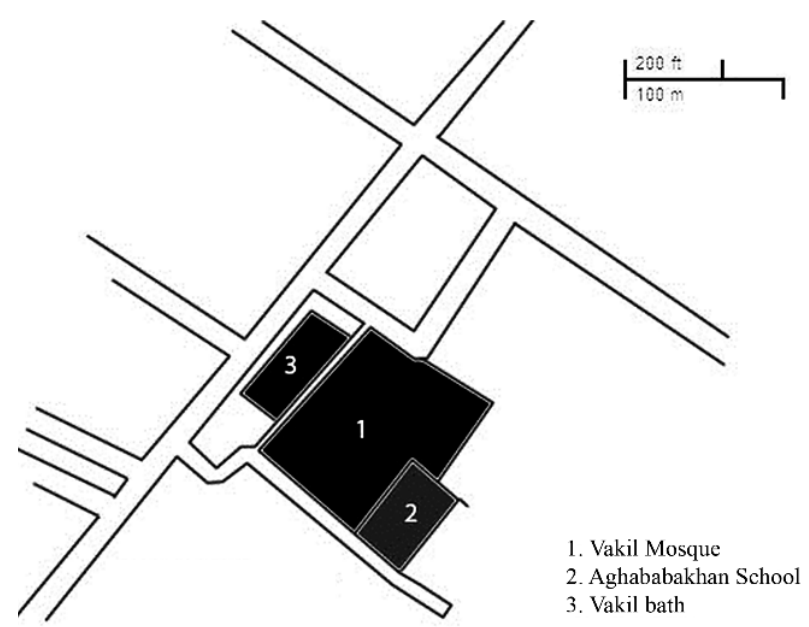

Fig. 8. Placement of the school next to the mosque (created by the author)
The design of historic mosques is in such a flexible way that allows many functions in different stages of a day or even at the same time. Historical mosques are mostly introvert and have an inside courtyard, shabestans ${ }^{2}$ and eyvans ${ }^{3}$. The number of shabestans and eyvans usually depends on the magnitude of the mosque. Usually shabestans were used as prayer halls and eyvans were used for educational purposes. The reason for having more than one shabestan and eyvan in mosques is that they could manage to have a desirable temperature, in every season in a year and every hour in a day without mechanical cooling or heating systems. Usually the west shabestan was used in summers and the east shanbestan was used in winters to capture the most desirable sunlight.

As it can be seen in the map (Fig. 9), the Nasiralmolk Mosque has two shabestans and one eyvan. The shabestans were mostly used for praying and religious purposes and the eyvan was mostly used for both educational and religious purposes. The reason behind the flexibility and multi-functionality of these spaces is that they are very simple large spaces with no furniture (Fig. 10).

In Shiraz, historical mosques were evenly distributed among the city to serve one, or sometimes two neighbourhoods (Fig. 11). These monumental mosques/schools were able to give a community identity to neighbourhoods and residents. Mosques in the historic urban design of Islamic cities such as Shiraz were a social symbol. Religious events and everyday life were good reasons for socializing and mosques were convenient places for these purposes. Islamic praying and rituals that occurred in mosques were mostly collective and the spatial configuration was designed to serve these rituals.

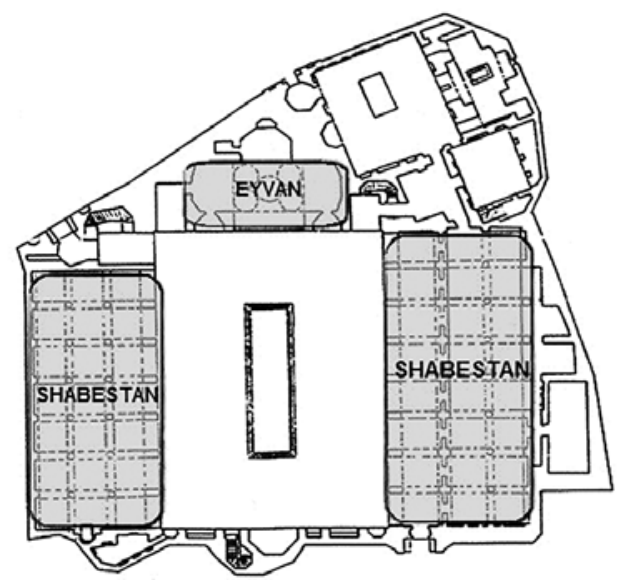

Fig. 9. Placement of Shabestan and Eyvan in Nasiralmolk Mosque (Behpoor map 1383)

${ }^{2}$ Shabestan is a large rectangular nave or hall with many visible piers or columns inside.

${ }^{3}$ Eyvan is a semi-outdoor rectangular space, usually vaulted, walled on three sides, with one end entirely open. 
Mostly, the land and sometimes the building were donated by a benefactor, to the mosque for public use. Therefore, these mosques cannot be considered as privatized spaces and they are usually owned and managed by public. In Shiraz the only government built mosque was Vakil Mosque, which is located next to the Vakil bazaar in the city centre and the local mosques could be considered as truly public amenities in historical neighbourhoods (Fig. 12).

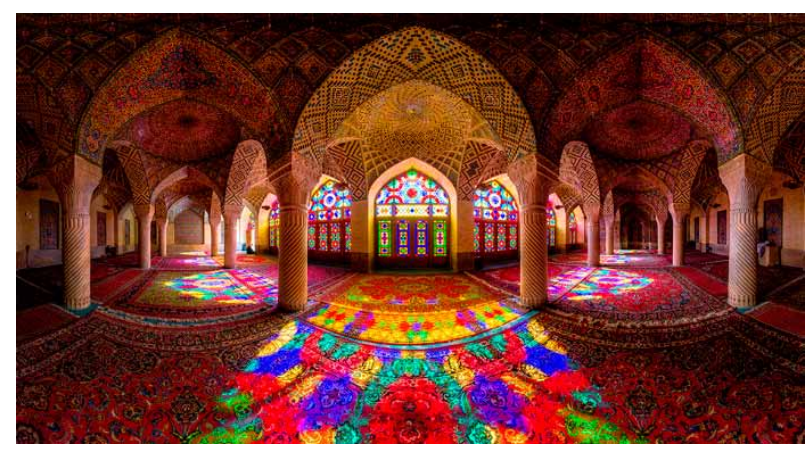

Fig. 10. Nasiralmolk West Shabestan (photo by Mohammad Reza Domiri Ganji)

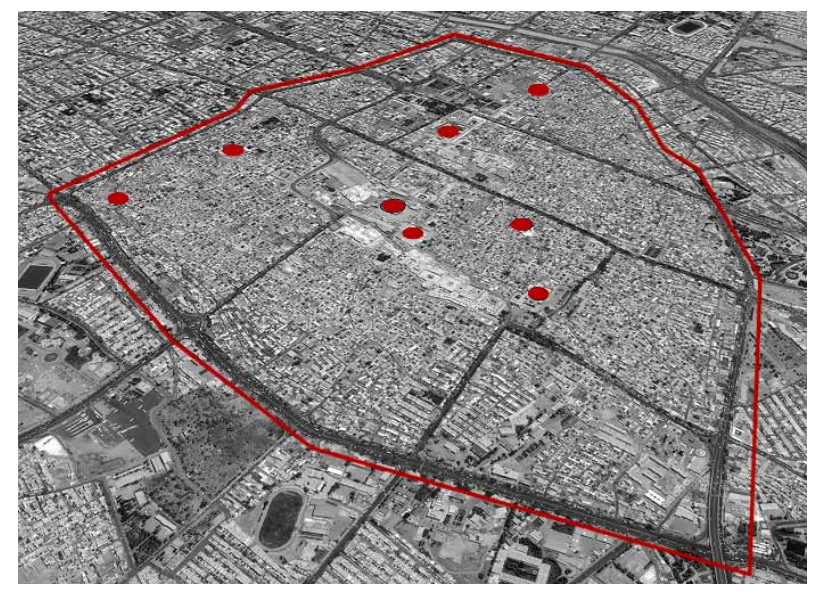

Fig. 11. Some mosques of Shiraz historical neighbourhoods (created by the author according to Google Earth Map)

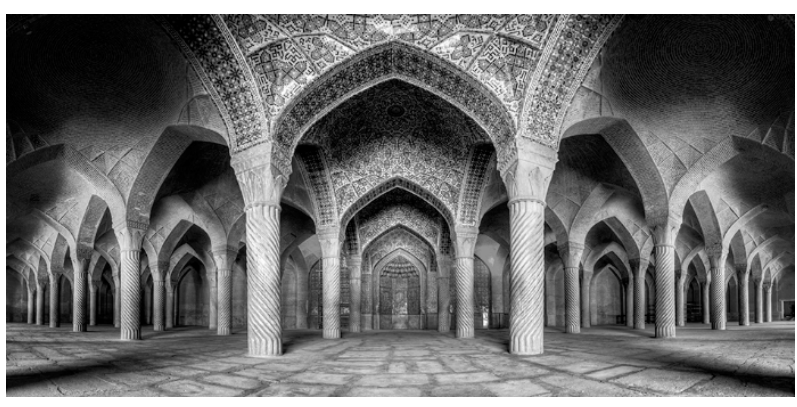

Fig. 12. Shabestan of Vakil Mosque (photo by Mohammad Reza Domiri Ganji)

\section{Baths}

In Islamic societies, washing the body has a special meaning for the purity of both body and soul. Taking a bath assures the ritual purity of the body, which is also considered as a requirement for daily praying. Similar to the ancient Roman Thermae, bathing in Iran was historically considered as a communal activity and baths (hammams) were frequently used for hygienic, religious and medical reasons, alongside socializing and relaxation. It was also a place for passing information and spreading rumours.

Public baths were divided into four main parts: an entrance, a cloakroom, a main door (middle corridor) and a hot chamber (garm khaneh), where washing took place (Fig. 13). The hot chamber, which is usually the largest space in the construction of hammams, is a convenient place for socialization. The hot chamber is usually an octagonal space with an octagonal pool in between surrounded by rectangular rooms. These rooms (hojre), which are usually vaulted with an aperture for light, are the place for people to rest, exchange news and interact (Fig. 14). A couple of small apertures are also embedded in the stone bench for keeping slippers or other objects. Hojres are usually on a higher level, in comparison to the hot chamber's floor, providing a semi-private area for socializing.

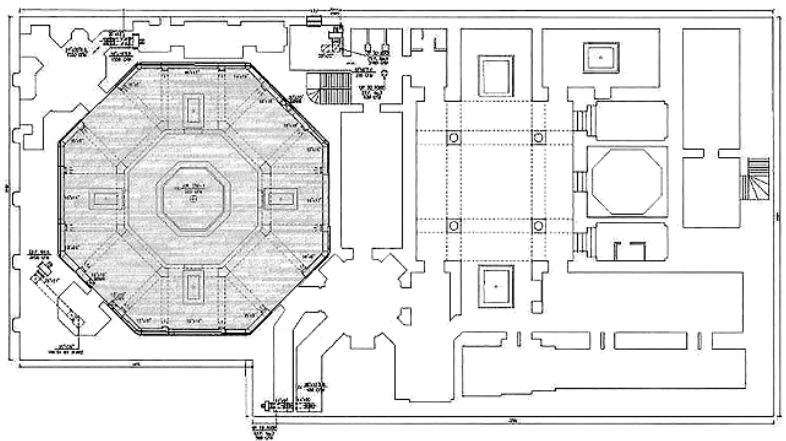

Fig. 13. Vakil Bath plan with highlighted hot chamber

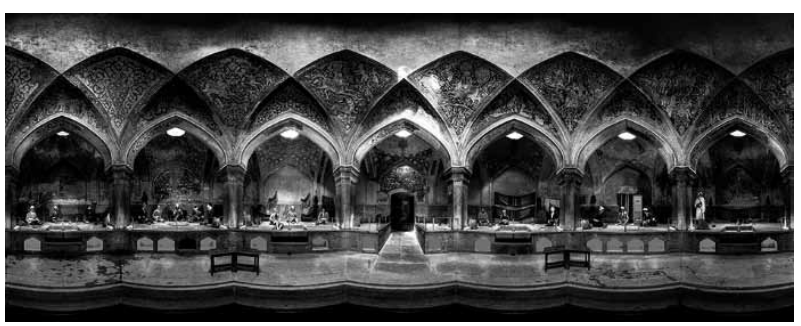

Fig. 14. Panoramic view of Vakil Bath Hot Chamber surrounding by small rooms for social encounters ( photo by Mohammad Reza Domiri Ganji) 
The social role of baths was especially significant for women, who were not as active as men were in civic participation. Women were usually responsible for household activities, while men provided for the family. Therefore, women's interactions in neighbourhoods were mostly limited to praying in mosques and using the bath or shopping. Each bath usually took about four hours, which gave people enough time to wash themselves and spend some time with neighbours or friends.

\section{Urban social elements in a larger scale}

The discussed elements of bath, mosque and school were considered as local social elements, gathering neighbours together. But, socio-historical elements of Shiraz were not exclusive to the neighbourhood level. There were similar socio-architectural elements, on a larger scale (city scale), which were able to provide an avenue for larger gatherings and social events in a much bigger scale than neighbourhoods were.

Shrine of Shahcheragh, Vakil Bazaar (market), and Khan Madrese (school) are among these elements. All these city scale buildings have their equivalents in the scale of neighbourhoods. The Shrine of Shahcheragh as a religious, social element can be compared to the role of a mosque in a neighbourhood. Vakil Bazaar, which is the main bazaar in Shiraz can also be the equivalent of local markets around neighbourhood centres and the Khan School can be compared to the mosque/schools in localities.

The Shrine of Shahcheragh that was located in the heart of the old city was accessible to almost all residents and localities. The religious figure of the building was raised by its social function (Fig. 15). Pilgrims from the whole city or even travellers from other cities gathered in the shrine to show their res-

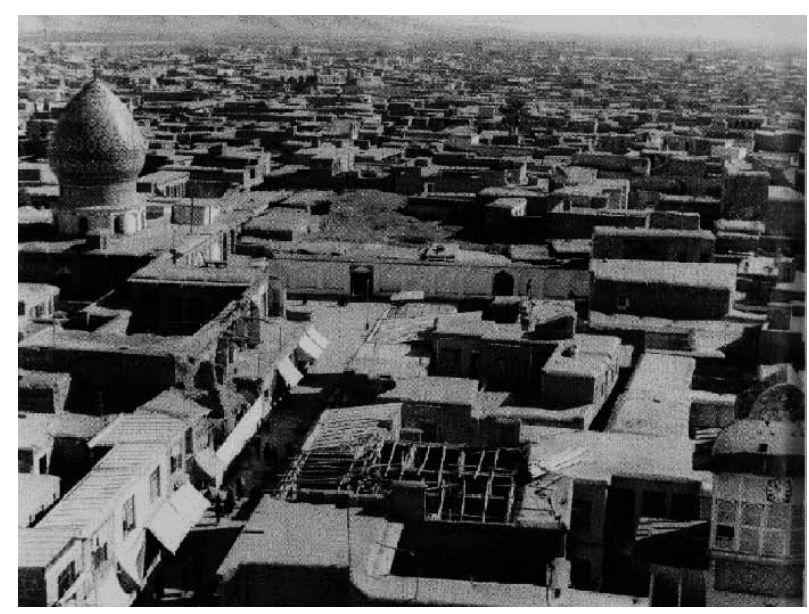

Fig. 15. Shahcheragh Shrine in old city of Shiraz in Ghajar Dynasty (Sane 1382) pect to the tomb and do their prayers. Sometimes, Shahcheragh Shrine was used as a known spot for religious gatherings at different times of a year (such as the commemoration of Ashura). A big courtyard and large flexible indoor prayer halls could make these gatherings possible.

It is worth mentioning that Vakil Bazzar and its nearby elements have had an important influence on promoting the social life of the historical city of Shiraz. As mentioned before, Vakil Bazaar is even considered as one of the contributing elements in the formation of the city of Shiraz. In small cities of Iran or rural areas in which the amount of commercial dealing with other cities was not high, the main part of the bazaar was to supply the internal needs of the urbanites. In larger productive cities such as Shiraz, neighbourhood markets had been in charge of providing daily needs of the residents, while the major part of the bazaar was for dealing with foreign commerce.

The social role of Vakil bazaar was not limited to commerce (Fig. 16). In historic cities of Iran, the bazaar was a place to celebrate important political occasions, or to express political disagreement and

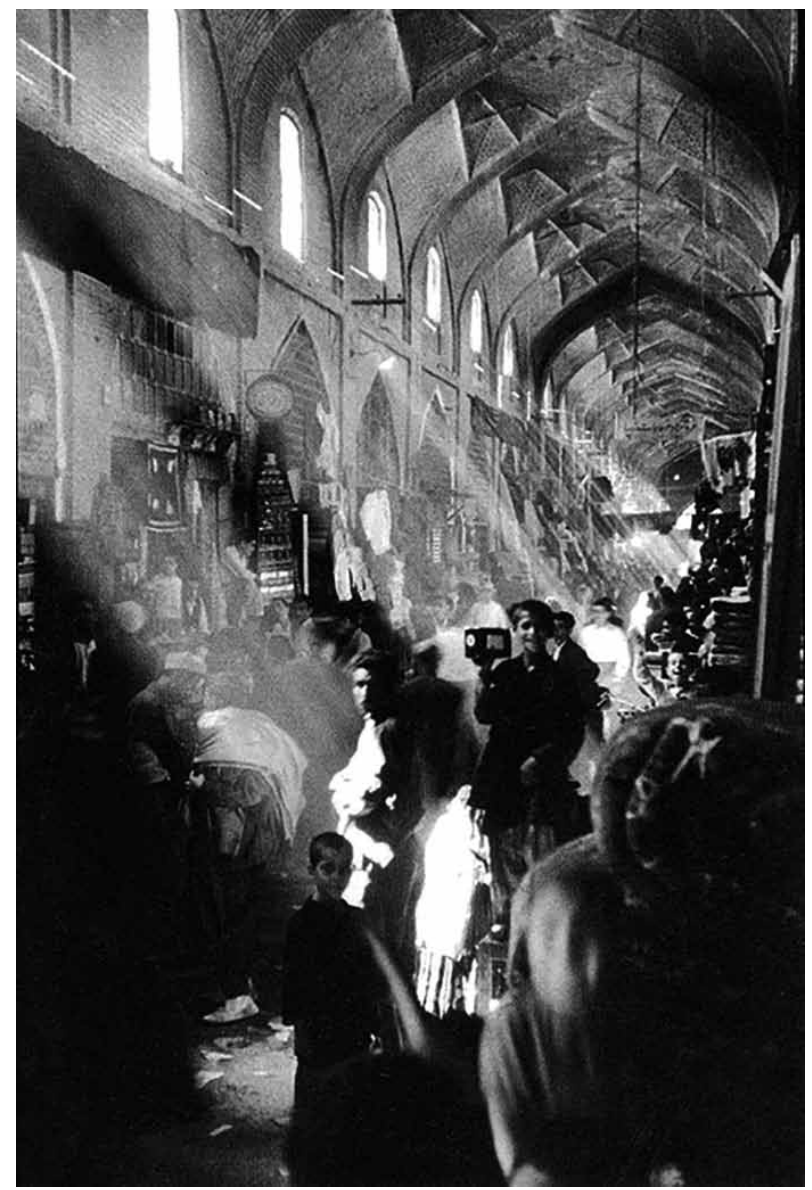

Fig. 16. Vakil Bazar in 1970 (Sane 1382) 
protest (Masoudi Nejad 2005). It was the main urban space to organize important ritual ceremonies: for instance, during the Ashura commemoration the function of a large number of commercial spaces was temporarily changed to provide a better space for the participants. The function of the bazaar as an urban use reinforced its public nature and increased interactions among different classes of society. The bazaar was also a place for the interchange of news and information (Moosavi 2004).

The social role of Vakil Bazaar is comparable to the social role of modern shopping malls. However, the difference is that shopping malls are usually built and maintained by private sectors for the exclusive goal of profit, but the bazaar was basically a public place in which commerce took place (through the private sectors). Therefore, the bazaar as a public space could have a multi-function and a social manifestation (although commerce was definitely the main function). In shopping malls, the design of food courts, which usually serve fast-foods, is in a way that encourages customers to eat hastily and continue shopping, while in bazaars, tearooms were 'third places' of interactions among customers or even salespersons.

The Khan School (Madrese Khan), which dates back to Safavid dynasty, was built for the speeches of Mollasadra, who is the most famous philosopher of Iran. Khan was a religious school in which students could live while taking courses. The school is composed of private spaces and public spaces. It contains about a hundred rooms, named hojreh which function in a similar way to modern dormitory spaces (Fig. 17), and five special spaces for speeches named madras (one of them was exclusive to Mollasadra's speeches).

The Khan School was a college for the city of Shiraz providing a social education space for residents. For important speeches and for attending Mollasadra's classes, residents gathered in the school from the whole

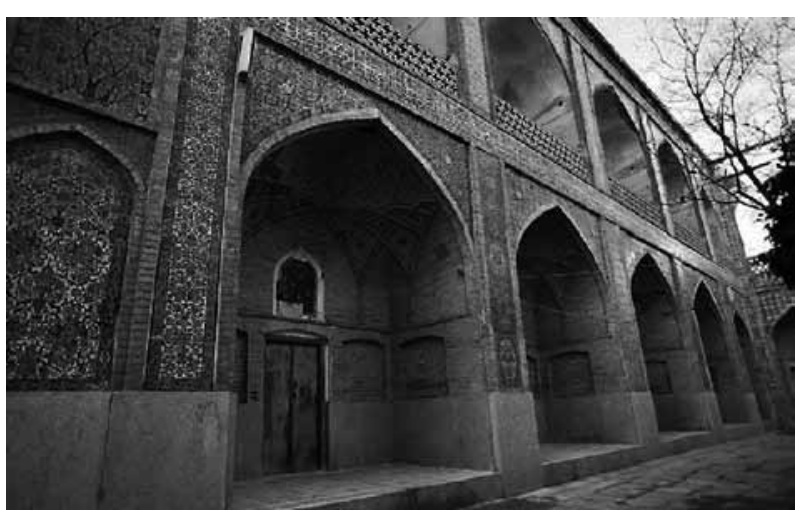

Fig. 17. Khan School dorms in the forms of small private rooms (photo by the author) city and even other cities and. As a result, this school with its critical location near Vakil bazaar is considered as a social element. It is clear that the reason behind the gatherings was educational and in this case philosophy acted as the 'community of interest' or 'common ties'. The school became the spatial arrangement for holding speeches and events.

\section{Conclusions}

Historically, social life and public places in neighbourhoods have been formed as a cohesive unit. Therefore, exploring the social life of historical vital neighbourhoods may introduce new approaches to the literature of the built environment by identifying the effective physical characteristics that promote social life in today's neighbourhoods.

A review of the literature showed that the five factors of density, human scale development, walkability, mixed land-use and the presence of public facilities and amenities were the factors that contributed the most to providing the social life of historical neighbourhoods in Shiraz. Additionally, the social structure of these public facilities were designed in a way that they could provide desirable social spaces in neighbourhoods and reinforce interactions. These public facilities were considered as truly 'third places', which were accessible to residential settlements.

Mosques, baths, narrow alleys and entrances, and neighbourhood centres were the social effective elements in creating the patterns of community in neighbourhoods. The creation of community is associated with three elements and these public facilities were able to provide the third component of community (place), considering the communal ties and interactions as the first and second. In Shiraz, the common ties among local communities were mostly religious and cultural. Not only were the public spaces and facilities of traditional settlements in Shiraz compatible with the culture, but also they were adaptable to the environment and were designed in regard to the residents' needs and requirements.

Each culture may introduce a new and different opportunity to the social configuration of neighbourhoods and communal facilities. Qualities of public spaces and amenities have been studied to have a contributing role in the social life of residential environments and a compatibility with the culture and residents' needs. Compatibility of the uses and public facilities and amenities to the culture and requirements of the residents may add to their qualities in terms of their social affordability and encouraging a social atmosphere in neighbourhoods. 


\section{Acknowledgements}

The authors would like to thank Dr David Beynon, Caroline Wright-Neville and Jane Allardyce for their valuable comments. Thanks also go to Bavand Behpour and Mohammad Reza Domiri Ganji for their help in providing the visual materials of this paper. The constructive comments provided by the anonymous referees are also gratefully acknowledged.

\section{References}

Alexander, C. 1977. A pattern language: towns, buildings, construction. New York: Oxford University Press.

Amick, D.; Kviz, F. 1975. Social alienation in public housing: the effects of density and building types, Ekistics 39: 118-120.

Appleyard, D. 1981. Livable streets. Berkeley: University of California Press.

Ashraf, A. 1988. Bazaar-mosque alliance: the social basis of revolts and revolutions, International Journal of Politics, Culture and Society 1(4): 538-567. http://dx.doi.org/10.1007/ BF01390687

Audirac, I.; Shermyen, A. H. 1994. An evaluation of neotraditional design's social prescription: postmodern placebo or remedy for suburban malaise?, Journal of Planning Education and Research 13(3): 161-173. http://dx.doi. org/10.1177/0739456X9401300301

Behpoor, B. 1383. Aesthetic analysis of three Ghajar buildings in Shiraz: Master Thesis, Shiraz University.

Bianchini, F. 1999. The crisis of urban public social life in Britain: origins, Planning Practice and Research 5(3): 4-8. http://dx.doi.org/10.1080/02697459008722770

Bonine, M. E. 1979. The morphogenesis of Iranian cities, Annals of the Association of American Geographers 69(2): 208-224. http://dx.doi.org/10.1111/j.1467-8306.1979.tb01252.x

Brower, S. N. 1996. Good neighborhoods: a study of in-town and suburban residential environments. Westport, Conn: Praeger.

Cohrun, S. E. 1994. Defining, understanding, and enhancing sense of community in neighborhoods, Journal of Planning Literature 9(1): 92-99. http://dx.doi.org/10.1177/ 088541229400900105

Farahani, L. M.; Lozanovska, M. 2014. A framework for exploring the sense of community and social life in residential environments, International Journal of Architectural Research: ArchNet-IJAR 8: 223-237.

Francis, J.; Giles-Corti, B.; Wood, L.; Knuiman, M. 2012. Creating sense of community: the role of public space, Journal of Environmental Psychology 32(4): 401-409. http:// dx.doi.org/10.1016/j.jenvp.2012.07.002

Franck, K. A.; Stevens, Q. 2007. Loose space: possibility and diversity in urban life. London: Routledge.

Gehl, J. 1980. Residential street environment, Building and Environment 6: 51-61.

Gehl, J. 1987. Life between buildings: using public space. Island Press.

Gehl, J. 2010. Cities for people. Washington: Island Press.

Gehl, J.; Gemzøe, L. 2004. Public spaces-public life. Arkitektens Forlag Kbh.

Gehl, J.; Svarre, B. 2013. How to study public life. Island Press. http://dx.doi.org/10.5822/978-1-61091-525-0
Gehl, J. J. G.; Kaefer, L. J. L. K.; Reigstad, S. S. R. 2006. Close encounters with buildings, Urban Design International 11: 29-47. http://dx.doi.org/10.1057/palgrave.udi.9000162

Hillery, G. A. 1955. Definitions of community: areas of agrrement, Rural Sociology 20: 111-123.

Jacobs, J. 1961. The death and life of great American cities. Vintage.

Kashef, M. 2009. Sense of community and residential space: contextualizing New Urbanism within a broader theoretical framework, International Journal of Architectural Research 3: 80-97.

Khaghani, S. 2012. Islamic architecture in Iran: poststructular theory and the architectural history of Iranian mosques. London: I. B. Tauris.

Kim, J.; Kaplan, R. 2004. Physical and psychological factors in sense of community new urbanist Kentlands and nearby Orchard Village, Environment and Behavior 36(3): 313-340. http://dx.doi.org/10.1177/0013916503260236

Kuo, F. E.; Sullivan, W. C.; Coley, R. L.; Brunson, L. 1998. Fertile ground of community: inner-city neighborhood common spaces, American Journal of Community Psychology 26(6): 823-851. http://dx.doi.org/10.1023/A:1022294028903

Langdon, P. 1997. A better place to live: reshaping the American suburb. University of Massachussetts Press.

Lockwood, C. 1997. Putting the urb in the suburbs: better late than never, Planning Chicago 63: 18-21.

Lund, H. 2002. Pedestrian environments and sense of community, Journal of Planning Education and Research 21(3): 301-312. http://dx.doi.org/10.1177/0739456X0202100307

Masoudi Nejad, R. 2005. Social bazaar and commercial bazaar: comparative study of spatial role of Iranian bazaar in the historical cities in different socio-economical context, in $5^{\text {th }}$ International Space Syntax Symposium Proceedings, 13-17 July 2005, Delft, Nederlands. 187-200.

Mehta, V. 2013. The street: a quintessential social public space. New York: Routledge.

Montgomery, J. 1998. Making a city: urbanity, vitality and urban design, Journal of Urban Design 3(1): 93-116. http:// dx.doi.org/10.1080/13574809808724418

Moosavi, M. S. 2004. Bazaar and its role in the development of Iranian traditional cities, in The $11^{\text {th }}$ Conference of the International Planning History Society (IPHS), 14-17 July 2004, Barcelona, Spain.

Motamed, N. 2000. Morphological dynamics of the eastern bazaar: MA thesis, University of Westminster.

Oldenburg, R. 1989. The great good place: cafés, coffee shops, community centers, beauty parlors, general stores, bars, hangouts, and how they get you through the day. New York: Paragon House.

Pendola, R.; Gen, S. 2008. Does "main street" promote sense of community? A comparison of San Francisco Neighborhoods, Environment and Behavior 40(4): 545-574. http://dx.doi.org/10.1177/0013916507301399

Plas, J. M.; Lewis, S. E. 1996. Environmental factors and sense of community in a planned town, American Journal of Community Psychology 24(1): 109-143. http://dx.doi. org/10.1007/BF02511884

Rapoport, A. 2007. The nature of the courtyard house: a conceptual analysis, Traditional Dwellings and Settlements Review $57-72$.

Sane, M. 1382. Be Yade Shiraz. Tehran: Sane. 
Soltanzadeh, H. 1986. History of city and urbanism in Iran. Tehran: Abi publications.

Talen, E. 1999. Sense of community and neighbourhood form: an assessment of the social doctrine of new urbanism, Urban Studies 36(8): 1361-1379. http://dx.doi. org/10.1080/0042098993033

Talen, E. 2000. The problem with community in planning, Journal of Planning Literature 15(2): 171-183. http://dx.doi. org/10.1177/08854120022092971

Wood, L.; Frank, L. D.; Giles-Corti, B. 2010. Sense of community and its relationship with walking and neighborhood design, Social Science and Medicine 70: 1381-1390. http:// dx.doi.org/10.1016/j.socscimed.2010.01.021

Zhang, W.; Lawson, G. 2009. Meeting and greeting: activities in public outdoor spaces outside high-density urban residential communities, Urban Design International 14: 207-214. http://dx.doi.org/10.1057/udi.2009.19

\section{LEILA M. FARAHANI}

School of Architecture and Built Environment, Deakin University, 1 Gheringhap Street, Geelong, 3220, Australia.

E-mail:lmahmoud@deakin.edu.au

Leila M. Farahani is a $\mathrm{PhD}$ candidate and research assistant at Deakin University, Australia. She started her studies and career in her hometown Shiraz, Iran. Her research interest includes community research, environment and behaviour research, public space and place making, and environmental psychology studies.

\section{MIRJANA LOZANOVSKA}

School of Architecture and Built Environment, Deakin University, 1 Gheringhap Street, Geelong, 3220, Australia.

E-mail: mirjana.lozanovska@deakin.edu.au

Dr Mirjana Lozanovska is Associate Head of School International and Senior Lecturer in the School of Architecture and the Built Environment at Deakin University. 